\title{
Regeneração natural do estrato arbustivo-arbóreo em área de Caatinga na Estação Ecológica do Seridó - RN, Brasil
}

\author{
Marcelo Silva de Lucena ${ }^{1 *}$ \\ Josuel Arcanjo da Silva ${ }^{1}$ \\ Allyson Rocha Alves ${ }^{2}$ \\ ${ }^{1}$ Universidade Federal de Campina Grande, Centro de Saúde e Tecnologia Rural \\ Bairro Santa Cecília, Caixa-Postal: 64, CEP 58700-970, Patos - PB, Brasil \\ ${ }^{2}$ Universidade Federal Rural do Semiárido, Mossoró - RN, Brasil \\ * Autor para correspondência \\ marceloslucena@hotmail.com
}

Submetido em 29/10/2015

Aceito para publicação em 18/03/2016

\section{Resumo}

Este trabalho objetivou avaliar a composição e a similaridade florística, o tipo de origem de regeneração e a influência de sistemas silviculturais sobre a diversidade e a densidade absoluta da regeneração do estrato arbustivo-arbóreo em duas áreas de Caatinga. A primeira encontra-se na Estação Ecológica do Seridó; a segunda, na Fazenda Pedro Cândido, ambas localizadas na cidade de Serra Negra do Norte, região do Seridó-RN. Utilizouse em cada área 16 subparcelas de $25 \mathrm{~m}^{2}$, em que foram incluídos indivíduos com CNB $\leq 6 \mathrm{~cm}$ e altura $>0,5$ $\mathrm{m}$. Estes foram classificados quanto ao tipo de origem de regeneração, se por sementes ou brotação de cepas. Calculou-se os parâmetros frequência, densidade, diversidade de Shannon, Equabilidade de Pielou e Similaridade Jaccard. Foram amostrados 2112 indivíduos, pertencentes a 13 espécies, 11 gêneros e sete famílias. Os valores de densidade, Shannon e Pielou, nos dois anos, divergiram, considerando as duas áreas. A regeneração por sementes predominou nas duas localidades. Após 22 e 24 anos das intervenções silviculturais, verificou-se que não houve influência dos tratamentos sobre a densidade e diversidade florística.

Palavras-chave: Diversidade; Fitossociologia; Semiárido; Sistemas Silviculturais

\section{Abstract}

Natural regeneration of the shrub-tree stratum in areas of caatinga at the Seridó Ecological Station, RN, Brazil. The objective of this study was to evaluate the composition and floristic similarity, regeneration origin and the influence of silviculture systems on the diversity and absolute density of regeneration of the shrub-tree stratum in two areas of Caatinga. The first area is in the Serido Ecological Station and the second is on Pedro Candido Farm, in the city of Serra Negra do Norte, in the Seridó region of RN, Brazil. In each area, 16 subplots of $25 \mathrm{~m}^{2}$ were delimited and individuals with a base circumference $\leq 6 \mathrm{~cm}$ and a height $>0.5 \mathrm{~m}$ were included in the study. The plants were classified according to origin of regeneration (seeds or budding). The following parameters were calculated: frequency, density, Shannon's diversity index, Pielou's evenness index and Jaccard's index. The sample included 2112 individuals belonging to 13 species, 11 genera and seven families. Considering the two areas, the values for density, Shannon's index and Pielou's index diverged in both years of the study. Regeneration by seeds was predominant in the two locations. After 22 to 24 years of silvicultural intervention, it was found that the treatments had no influence on density and floristic diversity.

Key words: Diversity; Phytosociology; Semiarid; Silvicultural systems 


\section{Introdução}

Apesar de vários estudos terem se preocupado com o entendimento dos mecanismos de regeneração natural em diferentes regiões da Caatinga, poucos são aqueles que abordam a regeneração natural sob a influência das diferentes formas de intervenção silvicultural.

Tendo em vista os diversos usos que se têm dado para os recursos florestais da Caatinga, principalmente a exploração dos recursos florestais para variadas maneiras de aproveitamento, primordialmente para geração de energia, é de fundamental importância o conhecimento dos diversos processos biológicos intrínsecos às espécies vegetais que compõem esse bioma, com especial atenção ao estrato arbóreoarbustivo, que é a principal fonte de lenha para as indústrias, olarias, cerâmicas, padarias, pequenos comércios e uso residencial no semiárido.

Sistemas silviculturais são ferramentas organizadas de operacionalização do manejo florestal. Esses sistemas podem objetivar a sustentação, a redução de danos à floresta, o aumento e a melhoria da produtividade de uma floresta existente ou a sua transformação ou substituição (PASSOS; BRAZ, 2004).

É de fundamental importância o conhecimento de informações básicas no que se refere aos impactos dos diferentes sistemas silviculturais sobre as características edáficas, condições de bancos de sementes do solo, serapilheira e como estes sistemas de uso dos recursos florestais podem afetar a capacidade de renovação do ecossistema, inclusive conhecer qual a possibilidade de se comprometer a capacidade de regeneração dos recursos da vegetação em ambientes de Caatinga.

Sampaio et al. (1998) afirmam que, diante dos diversos tipos de aproveitamento que se tem dado aos recursos florestais da Caatinga, é importante conhecer a capacidade de regeneração da vegetação nativa, com vistas ao estabelecimento de um manejo sustentável a longo prazo.

Constata-se, porém, uma grande escassez de informações ao que se refere à dinâmica biológica dos ecossistemas inseridos na Caatinga. Dessa maneira, os estudos de composição e regeneração natural são o ponto de partida para as propostas de manejo que se pode dar à Caatinga, levando em consideração que é necessário o aproveitamento conciliado com a sustentação do ecossistema.

Diante do exposto, o objetivo deste trabalho foi avaliar a composição e a similaridade florística, o tipo de origem de regeneração e investigar a influência de sistemas silviculturais sobre a diversidade florística e a densidade absoluta da regeneração do estrato arbustivoarbóreo em duas áreas de vegetação de Caatinga, nos anos de 2009 e 2011, na região do Seridó, no Rio Grande do Norte.

\section{Material e Métodos}

O estudo foi realizado em duas áreas contíguas, situadas no Rio Grande do Norte, município de Serra Negra do Norte. A primeira das áreas encontra-se na Estação Ecológica do Seridó (Esec do Seridó) (06 $35^{\prime}$ e $06^{\circ} 40^{\prime} S$; 37 $20^{\circ}$ ' e $\left.37^{\circ} 39^{\prime} \mathrm{W}\right)$, contando com uma superfície aproximada de 1.166 ha, enquanto a outra área está situada em propriedade particular, denominada Fazenda Pedro Cândido, localizada de forma contígua à Esec do Seridó. A área do experimento na Esec do Seridó é de aproximadamente 4 ha, enquanto na Fazenda Pedro Cândido é de 2,56 ha.

A região da Estação Ecológica do Seridó é caracterizada pelo clima semiárido do tipo BsW'h' (seco, muito quente e com estação chuvosa no verão) (KÖPPEN, 1996), e de acordo com os dados da estação meteorológica da Esec do Seridó, a temperatura média anual é de $30,7^{\circ} \mathrm{C}$, com média máxima em outubro $\left(31,0^{\circ} \mathrm{C}\right)$ e a mínima em fevereiro $\left(29,3^{\circ} \mathrm{C}\right)$. A umidade relativa do ar apresenta-se, aproximadamente, em torno de $50 \%$, com o máximo de $62 \%$ em fevereiro e o mínimo de $43 \%$ em novembro. A incidência solar alcança $2.800 \mathrm{~h}$ anuais.

A precipitação é variável entre os anos, desde 232,4 mm, em 1998, a 1.135,2 mm em 2002, com média anual atingindo $733,7 \mathrm{~mm}$. O período chuvoso se estende de janeiro a maio, com $86,5 \%$ do volume precipitado do ano, enquanto que em agosto-outubro, 
período mais seco do ano, chove apenas 2,2\% do volume total (SANTANA; SOUTO, 2006).

De acordo com a Classificação Brasileira de Solos (EMBRAPA, 2006), a região da Esec do Seridó apresenta solos luvissolos crômicos, pouco profundos, constituídos de material mineral, presença de horizonte B textural ou B nítico, elevado teor de nutrientes e saturação por base em torno de $80 \%$.

A vegetação de Caatinga representativa da região do Seridó é considerada hiperxerófila, com aspecto arbóreo-arbustivo esparso, cactáceas, estrato herbáceo efêmero e manchas de solo desnudas (COSTA et al., 2009).

$\mathrm{Na}$ Esec do Seridó, instalada em 1982, eram desenvolvidas atividades de pecuária e cultivo de algodão. Entre as perturbações anteriores à instalação da reserva, listam-se a construção de um açude, extração de madeira e introdução de espécies exóticas como algaroba e leucena (SIMON, 2004).

Os sistemas silviculturais compreenderam basicamente quatro tipos de corte, que eram associados com a presença não controlada de pastejo bovino, na Fazenda Pedro Cândido, e ausência total deste, na Estação Ecológica do Seridó.

Os dados utilizados neste estudo são referentes às medições realizadas em 2009 e 2011, no experimento instalado em ambas as áreas no ano de 1987. Na Esec do Seridó, não havia perturbação antrópica, pois o pastejo foi suspenso com a implantação da Unidade de Preservação. No outro experimento instalado na Fazenda Pedro Cândido, o pastejo continuou sendo praticado mesmo durante a realização do estudo.

O delineamento estatístico foi feito em blocos casualizados, nos quais foram aplicadas quatro modalidades de corte, com quatro repetições em dois blocos, sendo um bloco em cada uma das áreas estudadas. Os cortes foram: corte seletivo $\left(\mathrm{CS}_{+8}\right)$, em que foram cortadas as árvores com diâmetro na base maior que 8,0 cm (DNB > 8,0 cm); corte raso (CR), corte das árvores sem destoca e sem queima dos galhos restantes; corte raso com queima (CRQ), com corte raso das árvores e queima da galhada, porém sem destoca; e corte raso com destoca e queima da galhada (CRDQ).
Os dados foram coletados em subparcelas para análise da regeneração natural, as quais tinham uma área de $25 \mathrm{~m}^{2}$ (5,0 m x 5,0 m), segundo a Rede de Manejo Florestal da Caatinga (RMFC, 2005).

Foram avaliados os indivíduos com $\mathrm{CNB} \leq 6 \mathrm{~cm}$ e altura mínima de $0,5 \mathrm{~m}$. A utilização do critério de inclusão $\mathrm{CNB} \leq 6 \mathrm{~cm}$ e altura mínima $0,5 \mathrm{~m}$ serviu como parâmetro de contagem. Foi feito o registro das espécies, com identificação visual em campo, segundo parâmetros de identificação adotados pela Rede de Manejo Florestal da Caatinga (RMFC, 2005). As alturas dos fustes foram agrupadas em duas classes. A classe I continha os indivíduos de 0,5 a 1,0 $\mathrm{m}$ de altura, e a classe II, os indivíduos com altura acima de $1,0 \mathrm{~m}$ e com CNB até $6,0 \mathrm{~cm}$.

Em relação à origem da regeneração, os indivíduos foram agrupados para se averiguar se eram provenientes de germinação de sementes ou de rebrota de cepas. Considerou-se rebrota de cepa a planta arbórea em que a estrutura vegetativa se ramificava a partir de cepas; quando não, era considerada germinação de sementes.

A diversidade florística e equabilidade de espécies foram obtidas utilizando-se o Índice de Shannon-Weaver $\left(\mathrm{H}^{\prime}\right)$ e Equabilidade de Pielou (J), de acordo com as expressões abaixo (MATA NATIVA 3, 2011).

$$
\begin{gathered}
\mathrm{H}^{\prime}=\frac{\left[\mathrm{N} \cdot \operatorname{Ln}(\mathrm{N})-\sum_{\mathrm{i}=1}^{\mathrm{s}} \mathrm{n}_{\mathrm{i}} \operatorname{Ln}\left(\mathrm{n}_{\mathrm{i}}\right)\right]}{\mathrm{N}} \\
\mathrm{J}^{\prime}=\left(\frac{\mathrm{H}^{\prime}}{\mathrm{H} \max }\right)
\end{gathered}
$$

Em que:

H' = Índice de diversidade de Shannon-Weaver

$\mathrm{n}_{\mathrm{i}}=$ número de indivíduos amostrados na $i$-ésima espécie

$\mathrm{N}=$ Número total de indivíduos amostrados

$\mathrm{S}=$ número total de espécies amostradas

$\mathrm{Ln}=$ logaritmo de base neperiana

$\mathrm{J}=$ Equabilidade de Pielou

Hmáx $=\mathrm{L}_{\mathrm{n}}(\mathrm{S})$ 
A similaridade entre as áreas foi obtida mediante utilização do Índice de Similaridade de Jaccard $(S J)$, conforma a seguinte expressão (SOUZA; SOARES, 2013).

$$
S J=\frac{a}{a+b-c}
$$

Em que:

$\mathrm{a}=$ número de espécies ocorrentes na área 1

$\mathrm{b}=$ número de espécies ocorrentes na área 2

$\mathrm{c}=$ número de espécies comuns às duas áreas

No que diz respeito à fitossociologia, os parâmetros estudados foram a frequência e a densidade (absoluta e relativa) e o valor de importância (absoluto e relativo).

Para avaliar a influência dos sistemas silviculturais sobre a regeneração do estrato arbustivo-arbóreo, os valores de densidade e índices de diversidade (H' e J) e densidade absoluta (DA) foram submetidos a análises de comparações múltiplas das médias a $5 \%$ de probabilidade de erro pelo teste de Tukey $(\mathrm{P}<0,05)$. Para tal tarefa foi utilizado o programa Statistica 10 (2011).

A mensuração do CAP foi realizada com uso de fita métrica e a altura total com vara graduada. As análises fitossociológicas foram realizadas no software Mata Nativa 3 (2011).

\section{Resultados}

Verificou-se que não houve influência dos sistemas silviculturais sobre os parâmetros densidade absoluta (DA), Índice de Shannon (H') e Equabilidade de Pielou (J) das áreas analisadas, tanto em 2009 quanto em 2011, respectivamente, 22 e 24 anos após as intervenções (Tabela 1). Apesar da homogeneidade estatística entre os tratamentos, os valores observados para a densidade variaram de forma considerável entre as áreas, da mesma forma que H' e J para o ano de 2009.

Mesmo não havendo diferença significativa entre os sistemas silviculturais sobre a diversidade (H' e J) e densidade absoluta (DA) da regeneração do estrato arbustivo-arbóreo em ambos os anos nas duas localidades, observou-se uma sensível diferença para a diversidade e a densidade absoluta, no ano de 2009, quando se comparam as duas áreas, e para a densidade absoluta, no ano de 2011. Por esse motivo, a partir de então se optou por ponderar os resultados analisandose separadamente cada área. Considerando-se a proximidade das áreas, é válido lembrar que um dos principais fatores de divergência entre a Esec do Seridó e a Fazenda Pedro Cândido é o uso a que se destinam as áreas, pois a partir da instalação da Esec do Seridó, em 1982, foram cessadas as atividades antrópicas, enquanto na Fazenda Pedro Cândido as atividades antrópicas

TABELA 1: Médias da densidade absoluta, Índice de Shannon e Equabilidade de Pielou referentes aos tratamentos e aos blocos na Esec do Seridó e na Fazenda Pedro Cândido, município de Serra Negra do Norte - RN, para os anos 2009 e 2011

\begin{tabular}{|c|c|c|c|c|c|c|}
\hline \multirow{3}{*}{ Tratamentos } & \multicolumn{3}{|c|}{2009} & \multicolumn{3}{|c|}{2011} \\
\hline & \multicolumn{3}{|c|}{ Parâmetros Avaliados } & \multicolumn{3}{|c|}{ Parâmetros Avaliados } \\
\hline & DA & Shannon & Pielou & DA & Shannon & Pielou \\
\hline CR & $15400 \mathrm{a}$ & $0,79375 \mathrm{a}$ & $0,58000 \mathrm{a}$ & $12800 \mathrm{a}$ & $1,02750 \mathrm{a}$ & $0,64250 \mathrm{a}$ \\
\hline $\mathrm{CS}$ & $9900 \mathrm{a}$ & $0,95375 \mathrm{a}$ & $0,68125 \mathrm{a}$ & $10350 \mathrm{a}$ & $0,88875 \mathrm{a}$ & $0,62125 \mathrm{a}$ \\
\hline CRQ & $11650 \mathrm{a}$ & $0,72250 \mathrm{a}$ & $0,63375 \mathrm{a}$ & $12400 \mathrm{a}$ & $0,69250 \mathrm{a}$ & $0,67750 \mathrm{a}$ \\
\hline CRDQ & $19400 \mathrm{a}$ & $0,68250 \mathrm{a}$ & $0,59875 \mathrm{a}$ & $13700 \mathrm{a}$ & $0,69250 \mathrm{a}$ & $0,51750 \mathrm{a}$ \\
\hline \multicolumn{7}{|c|}{ Blocos } \\
\hline Esec do Seridó & $10600 b^{* *}$ & $0,99562 \mathrm{a} * *$ & $0,73438 a^{* *}$ & $9375 \mathrm{~b}^{* *}$ & $0,9075 \mathrm{a}^{* *}$ & $0,655625 \mathrm{a}^{* *}$ \\
\hline $\begin{array}{c}\text { Fazenda Pedro } \\
\text { Cândido }\end{array}$ & $17575 a^{* *}$ & $0,58062 b^{* *}$ & $0,51250 b^{* *}$ & $15250 \mathrm{a} * *$ & $0,74312 \mathrm{a}^{* *}$ & $0,57375 a^{* *}$ \\
\hline
\end{tabular}

DA: densidade absoluta; Shannon: Diversidade Medida pelo índice de Shannon; Pielou: Equabilidade de Pielou. Médias, nas colunas, seguidas pela mesma letra não diferem estatisticamente pelo Teste de Tukey ao nível de 5\% de significância. ** Significativo ao nível de $5 \%$ de probabilidade $(0,01=<\mathrm{p}<0,05)$ pelo teste de $\mathrm{F}$. 
estavam presentes, ressaltando-se o pastejo extensivo de gado bovino.

Na Esec do Seridó, no ano de 2009, foram amostrados 424 indivíduos vivos, pertencentes a 12 espécies, 10 gêneros e sete famílias botânicas. Duas espécies (Croton blanchetianus e Erythroxylum pungens) responderam por $64,86 \%$ dos indivíduos. As famílias mais representativas $(50,71 \%$ dos indivíduos) foram Euphorbiaceae, Fabaceae Mimosoideae e Combretaceae. No mesmo ano, na Fazenda Pedro Cândido, foram amostradas oito espécies, oito gêneros e seis famílias botânicas. Croton blanchetianus e Aspidosperma pyrifolium responderam por $90,18 \%$ do total. As famílias mais importantes foram Euphorbiaceae e Apocynaceae, com 63,01 e $27,74 \%$ dos indivíduos, respectivamente.

Em 2011, na Esec do Seridó foram encontradas 11 espécies, nove gêneros e sete famílias. Croton blanchetianus e E. pungens representaram $61,87 \%$ do total amostrado. Fabaceae Mimosoideae, Euphorbiaceae e Combretaceae foram as mais importantes $(52,53 \%$ do total de indivíduos). Na Fazenda Pedro Cândido, em 2011, observaram-se oito espécies, oito gêneros e cinco famílias, em que $C$. blanchetianus e $A$. pyrifolium responderam por $84,6 \%$ dos indivíduos. A maioria das espécies pertencia às famílias Euphorbiacea e Fabaceae Caesalpinioideae, as quais representavam 58\% dos indivíduos (Tabela 2).

Entre 2009 e 2011 a similaridade entre as áreas diminuiu, pois em 2009 o valor medido pelo Índice de Jaccard (SJ) era 0,67, enquanto em 2011 ele foi de 0,46 . A diversidade estimada pelos índices de ShannonWeaver (H') e a Equabilidade de Pielou (J') foi diferente para as duas áreas, em ambos os anos de estudados (Tabela 3).

TABELA 2: Relação florística de famílias, espécies e número de indivíduos (N) observados na Esec do Seridó e na Fazenda Pedro Cândido, município de Serra Negra do Norte - RN, nos anos de 2009 e 2011.

\begin{tabular}{|c|c|c|c|c|c|}
\hline \multirow{3}{*}{ Família/subfamília } & \multirow{3}{*}{ Nome científico } & \multicolumn{2}{|c|}{$\begin{array}{l}\text { Estação Ecológica } \\
\text { do Seridó }\end{array}$} & \multicolumn{2}{|c|}{$\begin{array}{c}\text { Fazenda Pedro } \\
\text { Cândido }\end{array}$} \\
\hline & & 2009 & 2011 & 2009 & 2011 \\
\hline & & $\mathbf{N}$ & $\mathbf{N}$ & $\mathbf{N}$ & $\mathbf{N}$ \\
\hline Apocynaceae & Aspidosperma pyrifolium Mart. & 28 & 31 & 195 & 179 \\
\hline Burseraceae & Commiphora leptophloeos (Mart.) J.B.Gillet & 3 & 4 & 0 & 0 \\
\hline \multirow[t]{2}{*}{ Combretaceae } & Combretum laxum Jacq. & 5 & 5 & 0 & 0 \\
\hline & Combretum leprosum Mart. & 33 & 33 & 39 & 71 \\
\hline Erythroxylaceae & Erythroxylum pungens O.E.Schulz & 112 & 90 & 1 & 0 \\
\hline \multirow[t]{3}{*}{ Euphorbiaceae } & Cnidoscolus quercifolius Pohl & 1 & 0 & 1 & 2 \\
\hline & Croton blanchetianus Baill. & 163 & 142 & 439 & 337 \\
\hline & Jatropha mollissima (Pohl) Baill. & 1 & 2 & 3 & 6 \\
\hline \multirow[t]{2}{*}{ Fabaceae Caesalpinioideae } & Poincianella pyramidalis (Tul.) L. P. Queiroz & 66 & 53 & 18 & 6 \\
\hline & Senna macranthera (Collad.) Irwin \& Barneby & 0 & 0 & 0 & 2 \\
\hline \multirow[t]{3}{*}{ Fabaceae Mimosoideae } & Anadenanthera colubrina & 5 & 8 & 0 & 0 \\
\hline & Mimosa ophthalmocentra Mart. ex Benth. & 5 & 5 & 0 & 0 \\
\hline & Mimosa tenuiflora (Willd.) Poir & 2 & 2 & 7 & 7 \\
\hline TOTAL & & 424 & 375 & 703 & 610 \\
\hline
\end{tabular}

TABELA 3: Valores dos Índices de diversidade de Shannon (H’) e Equabilidade de Pielou (J), em 2009 e 2011, Esec do Seridó e Fazenda Pedro Cândido, município de Serra Negra do Norte - RN.

\begin{tabular}{lcccccc}
\hline \multirow{2}{*}{\multicolumn{1}{c}{ Área }} & \multicolumn{2}{c}{$\mathbf{2 0 0 9}$} & \multicolumn{2}{c}{$\mathbf{2 0 1 1}$} & \\
\cline { 2 - 7 } & H' $^{\prime}$ & J' & Ja & H' & J' & Ja \\
\hline ESEC do Seridó & 1,63 nats.ind $^{-1}$ & 0,66 & \multirow{2}{*}{0,67} & 1,71 nats.ind $^{-1}$ & 0,71 & \multirow{2}{*}{0,46} \\
Fazenda Pedro Cândido & 0,99 nats.ind $^{-1}$ & 0,48 & & 1,12 nats.ind $^{-1}$ & 0,54 & \\
\hline
\end{tabular}


Quanto à estrutural horizontal, no ano de 2009, na Esec do Seridó, a densidade total foi de 10600 (N.ha $\left.{ }^{-1}\right)$, com dominância das C. blanchetianus (4075 N.ha ${ }^{-1}$ ) e E. pungens (2800 N.ha-1). Essas duas espécies apresentaram os maiores valores de importância, 26,48\% e $19,66 \%$, respectivamente. Entretanto, apesar de terem sido dominantes, apresentaram baixa frequência relativa (14,52 e 12,9\%, respectivamente). Na Fazenda Pedro Cândido, a densidade total foi de $17575\left(\mathrm{~N}^{-h^{-1}}\right)^{-1}$, com dominância das $C$. blanchetianus (10975 N.ha-1) e $A$. pyrifolium (4875 N.ha-1). Elas também apresentaram os maiores valores de importância, 44,95 e 28,57\%, respectivamente. Do mesmo modo como na área da Esec do Seridó, as espécies dominantes apresentaram baixa frequência relativa na área $(27,45$ e $29,41 \%)$. Três espécies (37,5\%) apresentaram menos de 100 indivíduos por hectare. Já em 2011, na Esec do Seridó, a densidade total de indivíduos foi $9375\left(\mathrm{~N}^{-} \mathrm{ha}^{-1}\right)$, com dominância de C. blanchetianus (3550 N.ha-1) e E. pungens (2250 N.ha $\left.{ }^{-1}\right)$. As referidas espécies também apresentaram os maiores valores de importância, 24,97 e 18,90\%, respectivamente. No tocante à Fazenda Pedro Cândido, a

TABELA 4: Densidade absoluta (DA), Densidade relativa (DR), Frequência absoluta (FA), Frequência relativa (FR) e Valor de importância (VI e VI\%) das espécies amostradas na Esec do Seridó e Fazenda Pedro Cândido, município de Serra Negra do Norte - RN, nos ano de 2009 e 2011.

\begin{tabular}{|c|c|c|c|c|c|c|c|c|c|c|c|c|c|}
\hline \multirow[t]{2}{*}{ Ano } & \multirow[t]{2}{*}{ Nome científico } & DA & DR & FA & FR & VI & $\begin{array}{c}\text { VI } \\
(\%)\end{array}$ & A & $\mathbf{R}$ & $\mathbf{A}$ & $\mathbf{R}$ & I I & $\begin{array}{c}\text { VI } \\
(\%)\end{array}$ \\
\hline & & \multicolumn{6}{|c|}{ Esec do Seridó } & \multicolumn{6}{|c|}{ Fazenda Pedro Cândido } \\
\hline \multirow{13}{*}{2009} & Aspidosperma pyrifolium & 700 & 6,6 & 56,25 & 14,52 & 21,12 & 10,56 & 4875 & 27,74 & 93,75 & 29,41 & 57,15 & 28,57 \\
\hline & Commiphora leptophloeos & 75 & 0,71 & 12,5 & 3,23 & 3,93 & 1,97 & - & 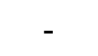 & 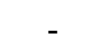 & - & . & - \\
\hline & Combretum leprosum & 825 & 7,78 & 56,25 & 14,52 & 22,29 & 11,15 & 975 & 5,55 & 43,75 & 13,73 & 19,27 & 9,64 \\
\hline & Combretum laxum & 125 & 1,18 & 12,5 & 3,23 & 4,41 & 2,205 & - & 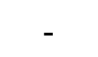 & - & - & - & - \\
\hline & Erythroxylum pungens & 2800 & 26,42 & 50 & 12,9 & 39,32 & 19,66 & 25 & 0,14 & 6,25 & 1,96 & 2,10 & 1,05 \\
\hline & Croton blanchetianus & 4075 & 38,44 & 56,25 & 14,52 & 52,96 & 26,48 & 10975 & 62,45 & 87,5 & 27,45 & 89,89 & 44,95 \\
\hline & Jatropha mo & 25 & 0,24 & 6,25 & 1,61 & 1,85 & 0,925 & 0,43 & 0,43 & 18,75 & 5,88 & 6,31 & 3,15 \\
\hline & Cnidos & 25 & 0,24 & 6,25 & 1,61 & 1,85 & 0,925 & 25 & 0,14 & 6,25 & 1,96 & 2,13 & 1,05 \\
\hline & Poinc & 1650 & 15,57 & 62,5 & 16,13 & 31,70 & 15,85 & 450 & 2,56 & 50 & 15,69 & 18,25 & 9,12 \\
\hline & Anadenanthera colubrina & 125 & 1,18 & 31,25 & 8,06 & 9,24 & 4,62 & - & 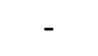 & - & - & - & - \\
\hline & Mimosa ophthalmocentra & 125 & 1,18 & 25 & 6,45 & 7,63 & 3,815 & - & - & - & - & - & - \\
\hline & Mimosa te & 50 & 0,47 & 12,5 & 3,23 & 50 & 1,85 & 175 & 1 & 12,5 & 3,92 & 4,92 & 2,46 \\
\hline & TOTAL & 0600 & 100 & 387,5 & 100 & 300 & 100 & 17575 & 100 & 318,75 & 100 & 300 & 100 \\
\hline \multirow{14}{*}{2011} & $A$ & & & 56,25 & 15,52 & 23,78 & 11,90 & 4475 & 29,34 & 87,5 & 28,57 & 57,92 & 28,96 \\
\hline & Commiphora leptophloeos & 1 & 1,07 & 12,5 & 3,45 & 4,51 & 2,26 & - & - & - & - & - & - \\
\hline & Combretum leprosum & 825 & 8,8 & 56,25 & 15,52 & 24,32 & 12,16 & 1775 & 11,64 & 56,25 & 18,37 & 30,00 & 15,01 \\
\hline & Combretur & & 1,33 & 18,75 & 5,17 & & 3,25 & - & - & - & - & - & - \\
\hline & Erythro & 2250 & 24 & 50 & 13,79 & 37,79 & 18,90 & - & - & - & - & - & - \\
\hline & Croton blanchetianus & 3550 & 37,87 & 43,75 & 12,07 & 49,93 & 24,97 & 8425 & 55,25 & 87,5 & 28,57 & 83,82 & 41,91 \\
\hline & Jatropha mollissima & 50 & 0,53 & 12,5 & 3,45 & 3,98 & 1,99 & 150 & 0,98 & 31,25 & 10,21 & 11,19 & 5,60 \\
\hline & Cnidoscolus quercifolius & 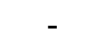 & - & - & - & - & 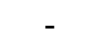 & 50 & 0,33 & 12,5 & 4,08 & 4,41 & 2,21 \\
\hline & Poincianella pyramidalis & 1325 & 14,13 & 62,5 & 17,24 & 31,37 & 15,69 & 150 & 0,98 & 12,5 & 4,08 & 5,06 & 2,53 \\
\hline & Senna macranthera & - & - & - & - & - & - & 50 & 0,33 & 6,25 & 2,04 & 2,37 & 1,19 \\
\hline & Anadenanthera colubrina & 200 & 2,13 & 25 & 6,9 & 9,03 & 4,52 & - & - & - & - & - & - \\
\hline & Mimosa ophthalmocentra & 125 & 1,33 & 18,75 & 5,17 & 6,51 & 3,25 & - & - & - & - & - & - \\
\hline & Mimosa tenuiflora & 50 & 0,53 & 6,25 & 1,72 & 2,26 & 1,13 & 175 & 1,15 & 12,5 & 4,08 & 5,23 & 2,62 \\
\hline & TOTAL & 9375 & 100 & 362,5 & 100 & 200 & 100 & 15250 & 100 & 306,25 & 100 & 200 & 100 \\
\hline
\end{tabular}


densidade total foi de $15250\left(\mathrm{~N} \cdot \mathrm{ha}^{-1}\right)$, com dominância de C. blanchetianus e A. pyrifolium, que foram as espécies de maior valor de importância na área (Tabela 4).

Com relação às classes de altura, em 2009, tanto na Esec do Seridó quanto na Fazenda, a maior densidade total estava presente na Classe II. Na Fazendo Pedro Cândido, em 2009, as espécies C. leprosum e Jatropha mollissima foram as únicas espécies a apresentar maior densidade na Classe I, sendo esta última exclusiva da primeira classe, indicando que provavelmente está em estágio inicial de sucessão secundária nessa área. Esse mesmo comportamento foi observado na área da Esec do Seridó para a referida espécie. Já em 2011, 85,60\% da densidade total dos indivíduos regenerantes na Esec do Seridó continuou presente na Classe II. Na Fazenda Pedro Cândido foi observada $80,98 \%$ da densidade total na classe II (Tabela 5).

No que diz respeito à origem da regeneração, no ano de 2009, na Esec do Seridó, 91,51\% do total da densidade era proveniente de sementes. As espécies C. leptophloeos, Combretum laxum, J. mollissima, Anadenanthera colubrina, Mimosa ophthalmocentra e Mimosa tenuiflora regeneraram-se exclusivamente a partir de sementes. Na Fazenda Pedro Cândido, as sementes também foram responsáveis por $84,49 \%$ do total da densidade. As espécies $C$. leprosum, $E$. pungens, Cnidoscolus quercifolius, J. mollissima e M. tenuiflora foram oriundas exclusivamente de regeneração por sementes. Já em 2011, na Esec do Seridó, a regeneração por sementes foi responsável por $77,87 \%$ do total da densidade e as espécies $C$. leptophloeos, C. laxum, J. mollissima, A. colubrina, M. ophthalmocentra e $M$. tenuiflora originaram-se exclusivamente por meio de sementes. Na Fazenda Pedro Cândido, foi visto que a regeneração a partir de cepas foi predominante, respondendo por $66,72 \%$ da densidade total. Entretanto, as espécies C. quercifolius, $J$. mollissima e Senna macranthera regeneraram-se exclusivamente através de sementes (Tabela 6).

TABELA 5: Distribuição da densidade (N.ha- $\left.{ }^{1}\right)$ de espécies quanto às classes de regeneração natural dos indivíduos amostrados nos anos de 2009 e 2011 na Esec do Seridó e Fazenda Pedro Cândido, município de Serra Negra do Norte - RN.

\begin{tabular}{lccccccccc}
\hline & \multicolumn{4}{c}{ Esec do Seridó } & \multicolumn{3}{c}{ Fazenda Pedro Cândido } \\
\cline { 2 - 9 } \multicolumn{1}{c}{ Nome científico } & \multicolumn{2}{c}{$\mathbf{2 0 0 9}$} & \multicolumn{2}{c}{$\mathbf{2 0 1 1}$} & \multicolumn{2}{c}{$\mathbf{2 0 0 9}$} & \multicolumn{2}{c}{2011} \\
\cline { 2 - 9 } & CR1 & CR2 & CR1 & CR2 & CR1 & CR2 & CR1 & CR2 \\
\hline Aspidosperma pyrifolium & 200 & 500 & 300 & 475 & 1075 & 3800 & 675 & 3800 \\
Commiphora leptophloeos & - & 75 & - & 100 & - & - & - & - \\
Combretum laxum & - & 125 & - & 125 & - & - & - & - \\
Combretum leprosum & 325 & 500 & 175 & 650 & 550 & 425 & 850 & 925 \\
Erythroxylum pungens & 300 & 2500 & 200 & 2050 & - & 25 & - & - \\
Cnidoscolus quercifolius & - & 25 & & & - & 25 & 50 & - \\
Croton blanchetianus & 350 & 3725 & 525 & 3025 & 1950 & 9025 & 1150 & 7275 \\
Jatropha mollissima & 25 & - & 25 & 25 & 75 & - & 100 & 50 \\
Poincianella pyramidalis & 100 & 1550 & 70 & 1250 & 50 & 400 & 25 & 125 \\
Anadenanthera colubrina & - & 125 & - & 200 & - & - & - & - \\
Mimosa ophthalmocentra & - & 125 & 25 & 100 & - & - & - & - \\
Mimosa tenuiflora & - & 50 & 25 & 25 & 25 & 150 & 25 & 150 \\
\hline \multicolumn{1}{c}{ TOTAL } & $\mathbf{1 3 0 0}$ & $\mathbf{9 3 0 0}$ & $\mathbf{1 3 5 0}$ & $\mathbf{8 0 2 5}$ & $\mathbf{3 7 2 5}$ & $\mathbf{1 3 8 5 0}$ & $\mathbf{2 9 0 0}$ & $\mathbf{1 2 3 5 0}$ \\
\hline
\end{tabular}

CR1: indivíduos de 0,5 a 1,0 m e CAP $\leq 6,0 \mathrm{~cm}$; CR2 com altura acima de $1,0 \mathrm{~m}$ e com CAP até $6,0 \mathrm{~cm}$. 
TABELA 6: Distribuição quanto à origem da regeneração, por meio da densidade (N.ha- ${ }^{-1}$ ), das espécies amostradas na Esec do Seridó e Fazenda Pedro Cândido, município de Serra Negra do Norte - RN, para os anos 2009 e 2011.

\begin{tabular}{|c|c|c|c|c|c|c|c|c|}
\hline \multirow{3}{*}{ Nome científico } & \multicolumn{4}{|c|}{ Esec do Seridó } & \multicolumn{4}{|c|}{ Fazenda Pedro Cândido } \\
\hline & \multicolumn{2}{|c|}{2009} & \multicolumn{2}{|c|}{2011} & \multicolumn{2}{|c|}{2009} & \multicolumn{2}{|c|}{2011} \\
\hline & RS & RT & RS & RT & RS & RT & RS & RT \\
\hline Aspidosperma pyrifolium & 500 & 200 & 475 & 300 & 3050 & 1825 & 1175 & 3300 \\
\hline Commiphora leptophloeos & 75 & - & 100 & - & - & - & - & - \\
\hline Combretum laxum & 125 & - & 125 & - & - & - & - & - \\
\hline Combretum leprosum & 675 & 150 & 550 & 275 & 975 & - & 150 & 1625 \\
\hline Erythroxylum pungens & 2750 & 50 & 1650 & 600 & 25 & - & - & - \\
\hline Cnidoscolus quercifolius & - & 25 & - & - & 25 & - & 50 & - \\
\hline Croton blanchetianus & 3675 & 400 & 2700 & 850 & 10125 & 850 & 3375 & 5050 \\
\hline Jatropha mollissima & 25 & - & 50 & - & 75 & - & 150 & - \\
\hline Poincianella pyramidalis & 1575 & 75 & 1275 & 50 & 400 & 50 & 125 & 25 \\
\hline Senna macranthera & - & - & - & - & - & - & 50 & - \\
\hline Anadenanthera colubrina & 125 & - & 200 & - & - & - & - & - \\
\hline Mimosa ophthalmocentra & 125 & - & 125 & - & - & - & - & - \\
\hline Mimosa tenuiflora & 50 & - & 50 & - & 175 & - & - & 175 \\
\hline TOTAL & 9700 & 900 & 7300 & 2075 & 14850 & 2725 & 5075 & 10175 \\
\hline
\end{tabular}

RS: Regeneração por sementes; RT: Regeneração a partir de cepas

\section{Discussão}

A semelhança estatística, no que se refere aos efeitos dos sistemas silviculturais sobre a regeneração do estrato arbustivo-arbóreo, é uma prova da resiliência da vegetação arbórea da Caatinga analisada no presente estudo, haja visto que os tratamentos aplicados variaram fortemente no que diz respeito ao grau de dano que podem causar à vegetação remanescente, indo desde $o$ corte seletivo até o corte raso com destoca e queima da galhada restante.

Araújo e Silva (2010) afirmam que antes da aplicação dos sistemas silviculturais, em 1989, as densidades absolutas nas parcelas dos tratamentos CR, CRDQ, CRQ e $\mathrm{CS}_{+8}$ eram respectivamente 2076, 2867, 1926 e 2280 (fustes.ha $^{-1}$ ) na Esec do Seridó; já na Fazenda Pedro Cândido os valores eram respectivamente de 2571, 2655, 1875 e 2204 (fustes.ha-1 ${ }^{-1}$ ), não havendo diferença significativa entres os valores nas duas áreas. Já em 2004, 15 anos após os tratamentos, as densidades de fustes com DAP igual ou superior a $1,5 \mathrm{~cm}$ para os tratamentos referidos anteriormente eram respectivamente de 3681 , 3788, 3550 e 4063 (fustes.ha-1) na Esec do Seridó, sem diferença significativa entre os tratamentos; enquanto na Fazenda Pedro Cândido os valores eram respectivamente de 4244, 3588, 1856 e 5494 (fustes.ha-1), com diferença significativa para $\mathrm{CS}_{+8}$ e CRQ. Eles também asseveram que não foram detectadas diferenças significativas entre as duas áreas ou nas interações.

Mesmo considerando o caráter drástico dos sistemas silviculturais utilizados (tipos de corte), percebe-se que, neste experimento, a densidade absoluta da vegetação do estrato arbustivo-arbóreo se mostrou indiferente ao tipo de corte, pois não houve diferença significativa na Esec do Seridó, assim como na Fazenda Pedro Cândido, 22 e 24 anos após as intervenções. Contudo, houve diferença significativa entre as áreas em ambos os anos. É válido esclarecer que em 2011 houve uma tendência de equiparação da densidade entre os tratamentos, com diminuição da densidade para CR e CRDQ e aumento para $\mathrm{CS}_{+8}$ e CRQ.

A diminuição em ambas as áreas pode ter sido motivada pela diminuição da precipitação entre os anos de 2009 e 2010, a qual, segundo a Emparn (2013), variou de mais de $1000 \mathrm{~mm}$ em 2009 até pouco mais de $200 \mathrm{~mm}$ em 2010, tornando a aumentar para entorno 
de $900 \mathrm{~mm}$ em 2011. Desse modo é possível asseverar que as condições de umidade são, entre outros fatores, fundamentais para o estabelecimento da regeneração da Caatinga do Seridó.

É importante frisar também que mesmo após o restabelecimento das condições de umidade, na área da Fazenda Pedro Cândido, a densidade de plantas na primeira na classe em 2011 foi menor em relação a 2009. As condições de uso da área podem ter contribuído para essa redução, uma vez que na Esec do Seridó houve aumento na densidade de plantas na primeira classe de altura.

Araújo e Silva (2010), comparando os efeitos dos mesmos tratamentos utilizados neste estudo, também na Esec do Seridó e Fazenda Pedro Cândido, observaram que o crescimento foi igual em relação aos tratamentos e às áreas e que, no que se refere à densidade, quinze anos após a aplicação dos tratamentos, na Esec do Seridó a recuperação se situou entre 122 e $258 \%$ do valor inicial (comparando médias de tratamentos) e na Fazenda Pedro Cândido esse mesmo parâmetro variou entre 98 e $280 \%$.

Pareyn et al. (2010), avaliando a eficiência do corte raso e quatro diferentes modalidades de corte seletivo em uma área de Caatinga arbustiva-arbórea, no Agreste Potiguar, com a presença de pastejo extensivo de gado bovino, concluíram que independentemente do tipo corte, presença de matrizes e do número de árvores residuais a densidade de plantas foi recuperada 11 anos após as intervenções, mostrando-se superior à inicial, e similar para todos os tratamentos. Os autores ainda observaram um aumento no número de espécies após 11 anos dos cortes.

Sampaio et al. (1998), em experimento realizado em Serra Talhada-PE, onde há vegetação de Caatinga, em que se aplicou corte raso, os autores verificaram que a densidade de espécies se recupera rapidamente, pois constataram que seis anos após o corte da vegetação a densidade atingiu o dobro da inicial, além de o acúmulo de biomassa ter sido constante nesse período, levando-os a concluir que as plantas da Caatinga, que por eles foram estudadas, rebrotam e crescem rapidamente após o corte.

Quanto à configuração da estrutura da regeneração em áreas do bioma caatinga, Lopes (2011) afirma que a recuperação da comunidade florestal em áreas antropogenicamente alteradas em ambientes semiáridos é direcionada pela dinâmica de ocupação por um pequeno número de espécies com alta densidade. Observa-se, nas áreas em regeneração, principalmente após agricultura ou pastagem, assim como também depois da retirada de lenha, que a composição florística tende a ser mais simples que antes, com a dominância de poucas espécies (SAMPAIO et al., 1998).

As interpretações devem ser cuidadosas, pois, além dos tratamentos, há a necessidade de se averiguar a influência de outras variáveis, que também podem ser importantes para a regeneração em ambientes de Caatinga. Neste contexto, cabe lembrar a pesquisa realizada por Lopes (2011), que, estudando duas fitofisionomias de Caatinga com vegetação arbustivaarbórea e clima Bsh (classificação climática de Köppen), em que uma delas se caracterizou por ser uma área preservada há pelo menos 50 anos, sem ser pastejada por gado bovino, e uma segunda área, que sofreu corte raso em 1994 para o cultivo de Opuntia ficus-indica Mill (palma gigante), a qual se regenera naturalmente, encontrou diferença significativa para o Índice de Shannon-Weaver e densidade da área preservada em relação ao campo em regeneração. A autora afirma que a densidade de indivíduos mostrou-se positivamente relacionada à precipitação, com diferença significativa $(\mathrm{t}=3,74 \mathrm{p}<0,01)$.

O número de espécies encontrado neste estudo pode ser considerado pequeno em relação a outras pesquisas realizadas em ambientes de Caatinga (e.g., ANDRADE et al., 2005; 2007; SANTOS et al., 2009; FABRICANTE et al., 2012) e até mesmo em levantamentos realizados na própria Estação Ecológica do Seridó, como é o caso do estudo realizado por Santana e Souto (2006), que encontram 2.448 indivíduos, representando 22 espécies, 20 gêneros e 12 famílias.

Andrade-Lima (1981) atribuiu às diferenças de precipitação a grande variabilidade no número de espécies encontradas em levantamentos florísticos e fitossociológicos na caatinga. Para ele, onde as precipitações são mais elevadas há maior número de espécies. Contudo, Rodal et al. (1992) ponderam que a variação no número de espécies não está atrelada 
somente ao total de precipitação, mas a um conjunto de fatores, como a topografia, classe, profundidade e permeabilidade do solo.

Além desses fatores, em locais da Caatinga que sofreram antropismo, como o corte raso, eliminação de árvores-matrizes e atividades pastoris, o número de espécies pode ser menor. Esse é o caso de uma pesquisa realizada por Fabricante e Andrade (2007), que, estudando uma região de Caatinga hiperxerófila, no Seridó Paraibano, que sofreu corte raso em 1964 e posteriormente utilizada para pastoreio bovino e caprino, e corte seletivo para fabricação de ferramentas, observaram 1129 indivíduos regenerantes, pertencentes a sete famílias, 12 gêneros e 15 espécies. Alves Junior et al. (2013), em estudo de regeneração natural de uma área de Caatinga, caracterizada por ser uma caatinga arbustivo-arbórea, com presença de cactáceas em Floresta-PE, região com predomínio de retirada de lenha para fabricação de carvão vegetal, adotando os mesmos critérios de amostragem utilizados neste estudo, encontram 15 espécies, pertencentes a sete famílias botânicas.

Santos et al. (2009), estudando a diversidade e densidade de três ambientes, dois com degradação crescente, com histórico de sobrepastejo e extração de lenha, e um terceiro ambiente conservado, observaram que o ambiente degradado apresentou o menor número de espécies, 28; o medianamente degradado, 44 espécies; e o conservado, o mais rico, com 50 espécies. Os resultados apontam que o processo de degradação vai sendo acompanhado pelo empobrecimento da flora, o que também foi observado em outros estudos (PEREIRA et al., 2001; 2003; MARACAJÁ et al., 2003).

A disparidade entre os resultados dos distintos trabalhos pode ser explicada também pelos diferentes critérios de amostragem utilizados ou mesmo pelo fato de vários trabalhos terem sido realizados objetivando o conhecimento do estrato adulto apenas, faltando parâmetros para comparar os ensaios que abordam a regeneração natural na Caatinga.

O sucesso da regeneração natural em florestas que sofreram algum tipo de intervenção depende, em grande parte, da distância das fontes de sementes, da abundância de árvores remanescentes, do tipo e da intensidade do manejo, o que inclui a introdução de gramíneas forrageiras, fogo, competição com o gado e a mecanização do manejo (KARIN; HAKAN, 1992).

A composição florística da regeneração arbórea de Caatinga das áreas estudadas mostrou-se caracterizada pela presença de uma grande quantidade de indivíduos distribuídos em poucas espécies que dominam a área. Apesar das ausências percebidas em cada localidade, o número de espécies mostrou-se estável entre os anos. Mas, quando se comparam as duas áreas, naquela em que o antropismo é mais acentuado, o número de espécies foi menor.

Vários trabalhos realizados na Caatinga têm listado as famílias Euphorbiaceae e Fabaceae como as de maior número de espécies (ANDRADE et al., 2005; 2007; FABRICANTE; ANDRADE, 2007; ALVES JUNIOR et al., 2013). O domínio dessas famílias em áreas de Caatinga que sofreram ou sofrem antropismo pode ser um indício de que elas possuem maior resistência aos danos provocados pelas intervenções e às diferentes formas de uso do solo.

A diminuição na similaridade entre os locais se deu em função da redução do número de espécies comuns entre as duas áreas. A diminuição ocorreu porque as espécies C. leptophloeos, C. laxum, A. colubrina e $M$. ophthalmocentra foram amostradas somente na área da Esec do Seridó, enquanto as espécies $C$. quercifolius e $S$. macranthera foram exclusivas da Fazenda Pedro Cândido, levando-se a inferir que, provavelmente, as várias formas de utilização dos recursos florestais têm provocado modificação na composição florística de diferentes locais, ainda que sob mesma tipologia florestal.

Em estudo realizado por Fabricante et al. (2012), que avaliou duas áreas de Caatinga hiperxerófila, em que uma das áreas sofria exploração com pecuária e corte seletivo, e outra com vegetação conservada desde 1980 , os autores observaram que os maiores valores de similaridade, medidos pelo do índice de Jaccard, ocorreram entre parcelas da mesma área, o que evidencia distinção entre as duas áreas.

Calixto Júnior e Drumond (2011), estudando a fitossociologia de um fragmento de Caatinga hiperxerófila 
que sofreu corte raso há 30 anos em Petrolina-PE, e que se regenera naturalmente, observaram que a vegetação da área avaliada se distingue floristicamente de outras áreas da Caatinga. Além da variação em atributos físicos de cada ambiente, a não similaridade entre as áreas deveuse aos diferentes níveis de antropismo.

Considerando-se a proximidade e o compartilhamento de características ambientais comuns entre as áreas avaliadas neste estudo, tais como a provável homogeneidade dos atributos físicos e químicos do solo e o regime climático, além do fato de as duas áreas serem compostas pela mesma tipologia florestal, pode-se inferir que, muito provavelmente, a redução na similaridade pode ser resultado de novas atividades antrópicas, como aumento na intensidade do pastejo, consorciado com os diferentes tipos de corte.

O maior número de espécies e a distribuição mais equitativa do número de indivíduos nas espécies da Esec do Seridó fizeram com que ela apresentasse os maiores valores nos dois anos. Os menores valores vistos na Fazenda Pedro Cândido podem ser explicados porque, além de ter apresentado menor número de espécies, houve uma forte dominância de $C$. blanchetianus. No ano de 2009, na área da Fazenda, a referida espécie contribuiu sozinha com cerca de $63 \%$ da densidade relativa, influenciando o componente abundância da diversidade.

Barbosa (2012) afirma que o grande domínio por C. blanchetianus provavelmente se deve ao fato de essa espécie ter grande capacidade de ocupar espaços abertos, em virtude da alta produção de sementes e da capacidade de dispersão destas, além de sua grande eficiência na utilização de nutrientes. Soma-se a isto o fato de essa espécie não ser forrageada pelo gado bovino nem atacada por cupins, mostrando-se superior tanto em relação às demais espécies, para o parâmetro densidade, quanto nas classes de regeneração nas áreas nas áreas de Caatinga em estado de sucessão secundária.

Assim sendo, evidencia-se, provavelmente, que o gado atua como um agente capaz de realizar o favorecimento a certas espécies que não são palatáveis, reduzindo a competição dessas espécies com as demais, que podem usadas para sua alimentação. Esse fato pode ser mais claramente compreendido quando se observa que na área da Esec do Seridó, apesar de o C. blanchetianus ter apresentado o maior número de indivíduos e a maior densidade relativa, a contribuição das espécies foi mais equitativa. Isso explica, muito provavelmente, que a variação entre as áreas é fruto da diferenciação no grau de antropização de ambas os locais, conforme visto, para riqueza de espécies, gênero e família.

Os valores de H' deste trabalho, em ambas as áreas, foi menor do que os encontrados por Santana e Souto (2006), que, inventariando indivíduos arbustivoarbóreos em locais preservados da Esec do Seridó, os quais mediram indivíduos com $\mathrm{DNB}>3 \mathrm{~cm}$ e altura maior que $1 \mathrm{~m}$, obtiveram um valor de $\mathrm{H}^{\prime}$ igual a 2,35 nats. ind $^{-1}$, o que nos levar a inferir que a pressão antrópica é um fator que pode causar redução da diversidade nas áreas de estudo.

De acordo com Araújo e Silva (2010), antes da aplicação das intervenções silviculturais, em 1989, os valores para Índice de diversidade de Shannon referentes às parcelas dos tratamentos $\mathrm{CR}, \mathrm{CRDQ}, \mathrm{CRQ}$ e $\mathrm{CS}_{+8}$, eram respectivamente 2,07, 1,81, 2,01 e 2,07, na Esec do Seridó; enquanto na Fazenda Pedro Cândido, os valores para os referido tratamentos eram respectivamente 1,69, 1,62, 1,65 e 1,77 nats.ind ${ }^{-1}$. Após 15 anos (2004), os valores, na Esec do Seridó, eram respectivamente de $1,77,1,51,1,92$ e 2,01 nats.ind $^{-1}$, demonstrando uma tendência de diminuição para todos os tratamentos. Já na Fazenda Pedro Cândido, também em 2004, houve aumento do referido índice para todos os tratamentos, assumindo, respectivamente os valores de 1,77, 1,51, 1,39 e 1,81 nats.ind ${ }^{-1}$. Em 2004, os autores lembram que, nos conjuntos dos dois locais, a riqueza total era de 24 espécies, em que a Esec do Seridó tinha 22 espécies, e a Fazenda Pedro Cândido, 16. Antes da aplicação dos tratamentos o número de espécies era 13 para cada área.

No presente trabalho se verificou que tanto em 2009 quanto em 2011 não houve diferença significativa entre as modalidades de corte na regeneração do estrato arbustivo-arbóreo. Contudo, entre as áreas, em 2009, houve diferença significativa, tendo a Esec do Seridó assumido o maior valor para H'. Isso se deve ao fato de na Esec do Seridó terem sido registradas 12 espécies, 
enquanto na Fazenda Pedro Cândido, oito espécies. Nas duas áreas, o número total de espécies em 2011 era 13.

Pôde-se observar que 11 espécies que foram registradas por Araújo e Silva (2010) não foram amostradas neste estudo. Essas espécies dizem respeito àquelas que apresentaram baixa frequência, tais como Jucá, Pau-d'arco, Jurema-lambe-beiço, AngicoManso, Feijão Bravo, Pau-Piranha, Marmaleirobranco, Umbuzeiro etc. O fato de essas espécies apresentarem baixa densidade dificultou sua inclusão na amostragem. Ainda se pode depreender que, no momento das intervenções silviculturais, os cortes drásticos (CR, CRQ e CRDQ) não podem ser aplicados a árvores consideradas raras para a área, sob o risco de dificultar ou mesmo impedir a regeneração dessas espécies.

Fabricante et al. (2012), estudando duas áreas de Caatinga hiperxerófila na região do Submédio São Francisco (Petrolina/Juazeiro), estimaram valores de $\mathrm{H}^{\prime}$ de 1,886 e 2,688 nats.ind ${ }^{-1}$, e J' $=0,572$ e 0,734, respectivamente, para as áreas explorada e conservada.

Freitas et al. (2007), realizando um estudo em duas áreas de Caatinga em Messias Targino-RN, em que a área I refere-se à que sofreu antropismo, com a retirada de madeira para construção de cercas e pastejo, e a área II, mais antropizada, utilizada ultimamente para pastejo e na qual, entre a década de 1920 e 1980, existiu o cultivo do algodão mocó, encontraram, respectivamente, para as duas áreas os seguintes valores de H': 1,44 e 0,19 nats.ind ${ }^{-1}$.

Os valores encontrados por estes últimos autores assemelham-se aos obtidos neste trabalho, e possibilita verificar a mesma tendência, em que o ambiente mais degradado apresenta a menor diversidade.

Analisando-se separadamente cada área, foi visto que a densidade absoluta total da Esec do Seridó diminui no decorrer dos dois anos, explicada pelo fato de algumas espécies não terem sido inventariadas, além da diminuição na densidade de $C$. blanchetianus. Já em relação à Fazenda Pedro Cândido, também houve diminuição da densidade absoluta no período de tempo considerado.

Apesar de, na área da Fazenda Pedro Cândido, o número de espécies ter sido menor nos dois anos, ela conseguiu propiciar as maiores densidades totais observadas, em função, principalmente, da grande concentração de $C$. blanchetianus. Mesmo tendo sido encontrados na Fazenda Pedro Cândido os maiores valores para densidade, o comportamento das áreas foi semelhante, pois em ambos os anos houve concentração de uma grande densidade em um pequeno número de espécies.

Pereira et al. (2001), estudando a regeneração natural em um fragmento de Caatinga com diferentes níveis de perturbação no agreste paraibano, concluíram que o antropismo afetou a regeneração natural arbórea. Observaram que a influência foi mais clara sobre a densidade, distribuição espacial e composição florística, apontando $C$. blanchetianus como uma espécie indicadora de perturbação.

Alves et al. (2010) afirmam que o C. blanchetianus se sobressai em relação às demais espécies, por ela ser uma pioneira, típica de áreas antropizadas, de fácil dispersão, contribuindo para o enriquecimento do banco de sementes do solo, dominando os primeiros estágios de sucessão ecológica em áreas sob grandes perturbações.

Os resultados encontrados neste trabalho para o estrato arbustivo-arbóreo da regeneração natural no ambiente experimental diferem daqueles encontrados por Santana e Souto (2006), que mensuraram também na Esec do Seridó, em localidade resguardada de intervenções, os indivíduos com DNS $>3 \mathrm{~cm}$ e altura maior que $1 \mathrm{~m}$, e observaram que $C$. blanchetianus, Poincianella pyramidalis, A. pyrifolium apresentaram $26,18,17,16$ e $15,32 \%$, respectivamente, para a densidade relativa. Essas mesmas espécies também apresentaram os seguintes valores para o VI\%: 50,06, 54,27 e $51,22 \%$, respectivamente.

Entretanto, observa-se que o comportamento da regeneração não foi o mesmo observado pelos referidos autores, quando se analisam as duas áreas separadamente, pois enquanto na Esec do Seridó as três espécies com os maiores valores de densidade relativa e valor de importância relativa foram, respectivamente, C. blanchetianus, E. pungens e P. pyramidalis; na Fazenda Pedro Cândido as três espécies que apresentaram os maiores valores para os parâmetros 
apontados foram respectivamente $C$. blanchetianus, $A$. pyrifolium e C. leprosum.

Meunier e Carvalho (2000) registraram para o estrato adulto que antes da aplicação dos tratamentos, em 1989, na área da Esec, as três espécies com maior densidade relativa eram respectivamente $P$. pyramidalis, C. leprosum e C. blanchetianus, enquanto na Fazenda Pedro Cândido as três espécies que tinham a maior densidade relativa eram $C$. leprosum, $C$. blanchetianus e A. pyrifolium. Após 15 anos da aplicação dos tratamentos, Araújo e Silva (2010) observaram que na Esec do Seridó as espécies com maior densidade relativa eram respectivamente $P$. pyramidalis, $M$. tenuiflora e C. blanchetianus, enquanto na Fazenda Pedro Cândido quem ocupavam essas posições eram, respectivamente, M. ophthalmocentra, P. pyramidalis e M. tenuiflora.

As intervenções exerceram uma influência na composição do componente adulto, da mesma forma que a regeneração natural das duas áreas foi influenciada, tanto em relação à composição das espécies quanto em relação à densidade e a importância das espécies para a comunidade florestal.

Uma possível explicação para que a maioria de indivíduos fosse amostrada na segunda classe de altura pode ser o fato de estes terem superado a fase plântula e ganhado condições de sobrevivência e, posteriormente, ingressado para classes superiores, não atendendo, assim os critérios de inclusão adotados.

Entretanto, Alves Junior et al. (2013) afirmam que o menor número de indivíduos das menores classes de tamanho pode ser explicado pelo fato de eles serem mais suscetíveis à mortalidade, enquanto a variação no número de indivíduos das classes maiores ocorre pelo fato de os indivíduos mudarem de classe. Isso se confirma pelo fato de ter havido diminuição da densidade no decorrer do período observado na Fazenda nas duas classes, como também diminuição na segunda classe da Esec do Seridó. É importante frisar que os levantamentos foram realizados após o mês de setembro dos anos de 2009 e 2011, período em que as condições de umidade caem bastante, e que isso pode contribuir para a morte de muitas plântulas.

Alves e Metzger (2006) afirmam que o insucesso no estabelecimento pós-dispersão ocorre basicamente devido a mudanças nas taxas de germinação, competição, herbivoria e estresse hídrico e microclimático, que alteram a sobrevivência e o crescimento de plântulas.

A regeneração natural em áreas semiáridas pode ser influenciada por uma série de fatores, tais como dispersão de sementes, presença de um banco de sementes, condições de solo e as limitações impostas pela disponibilidade hídrica (MIRANDA et al., 2004).

Assim, não se pode afirmar com certeza que o comportamento observado para as duas áreas aponta para o fato de a comunidade florestal ter superado as fases iniciais de estabelecimento, influenciada principalmente pelo ingresso dos indivíduos na classe II, uma vez que a mortalidade na primeira classe deve ser considerada, principalmente em ecossistemas onde a umidade é limitante ao crescimento das plantas, tal como são as áreas de Caatinga.

Apesar de a rebrota contribuir para uma rápida regeneração de áreas antropizadas, a germinação de sementes é uma estratégia de elevada importância para a recuperação de áreas de ambientes secos. Porém, fatores que afetam a chuva ou a sobrevivência das sementes no solo exercem forte influência na regeneração de áreas que sofreram intervenção humana. Assim, observouse que tanto na Esec do Seridó quanto na Fazenda Pedro Cândido houve espécies que se regeneraram exclusivamente a partir de sementes, enfatizando a importância da adoção de sistemas de intervenção que preservem árvores matrizes, agridam minimamente o banco de sementes e conservem as características físicoquímicas do solo.

Alves et al. (2010), ao estudarem uma área que sofreu desmatamento em 1976 e 1977 para cultivo de algodão, deu lugar ao pastejo bovino e é usada atualmente para retirada de madeira, afirmam que, mesmo mediante ação antrópica e presença de gado bovino na área de estudo, o fragmento está avançando no processo sucessional e que o fator primordial e indispensável para explicar essa situação é o modo como tem ocorrido a regeneração vegetal, já que $80 \%$ do total de indivíduos são oriundos de sementes, 
enquanto o restante provém de regeneração por rebrota de cepas.

Em florestas tropicais secas, a dispersão das sementes ocorre prevalentemente ao final da estação chuvosa ou mesmo em pleno período de seca, com predominância de sementes pequenas e em grande quantidade, com pouco conteúdo de água, o que lhes garante menor dissecação. Além disso, são dispersas por anemocoria, apresentam dormência, de maneira que elas têm a capacidade de permanecer no solo por mais tempo, de forma que quando tem início o período chuvoso, em que há grande quantidade de umidade, encontram condições para geminação e estabelecimento (VIEIRA; SCARIOT, 2006).

Sampaio et al. (1998) afirmam que o corte nas espécies da Caatinga tem efeito direto em processos fisiológicos, induzindo, na maioria das plantas, uma atividade meristemática intensa para a regeneração do sistema aéreo, com gasto de reservas acumuladas nos sistemas subterrâneos e nos tocos de caules. Kennard et al. (2002) afirmam que a rebrota é especialmente importante em ambientes secos, haja vista a limitação na umidade, pois o sistema radicular das cepas proporciona uma maior área de superfície para absorção de água, podendo alcançar umidade e nutrientes em camadas mais profundas do solo.

Por sua vez, quando se comparam os valores da densidade de regeneração a partir de cepas, na área da Fazenda, entre os anos de 2009 e 2011, pode-se inferir que, diante de novas intervenções sobre a vegetação da área de estudo, a brotação a partir de cepas pode ser a estratégia de regeneração predominante, principalmente porque os sistemas de intervenção podem ocasionar alterações no banco de sementes do solo, a eliminação de árvores matrizes, além de ausência de fauna que promova a dispersão.

\section{Agradecimentos}

À Rede de Manejo Florestal da Caatinga pela disponibilização das fichas de campo, referentes às medições.

\section{Referências}

ALVES, L. F.; METZGER, J. P. A regeneração florestal em áreas de floresta secundária na Reserva florestal do Morro Grande, Cotia, SP. Biota Neotropica, Campinas, v. 6, n. 2, 2006.

ALVES, L. S.; HOLANDA, A. C.; WANDERLEY, J. A.; SOUZA, J. S.; ALMEIDA, P. G. Regeneração natural em uma área de Caatinga situada no município de Pombal - PB, Brasil. Revista Verde de Agroecologia e Desenvolvimento Sustentável, Mossoró, v. 5, n. 2, p. 152-168, 2010.

ALVES JUNIOR, F. T.; FERREIRA, R. L. C.; SILVA, J. A.; MARANGON, L. C.; CÉSPEDES, G. H. G. Regeneração natural de uma área de Caatinga no Sertão Pernambucano, Nordeste do Brasil. Revista Cerne, Lavras, v. 19, n. 2, p. 229-235, 2013.

ANDRADE-LIMA, D. The caatingas dominium. Revista Brasileira de Botânica, São Paulo, v. 4, n. 2, p. 149-153, 1981.

ANDRADE, L. A.; OLIVEIRA, F. X.; NEVES, C. M. L.; FELIX, L. P. Análise da vegetação sucessional em campos abandonados no agreste paraibano. Revista Brasileira de Ciências Agrárias, Recife, v. 2, n. 2, p. 135-142, 2007.

ANDRADE, L. A.; PEREIRA, I. M.; LEITE, U. T.; BARBOSA, M. R. V. Análise da cobertura de duas fitofisionomias de Caatinga com diferentes históricos de uso, no município de São João do Cariri, estado da Paraíba. Revista Cerne, Lavras, v. 11, n. 3, p. 253-262, 2005.

ARAÚJO, L. V. C.; SILVA, J. A. Unidade experimental estação ecológica do Seridó - RN. In: In: GARIGLIO, M. A.; SAMPAIO, E. V. S. B.; CESTARO, L. A.; KAGEYAMA, P. Y. (Org.). Uso sustentável e conservação dos recursos florestais da Caatinga. Brasília: Serviço Florestal Brasileiro, 2010. p. 215-228.

BARBOSA, M. D. Composição florística, regeneração natural, decomposição e ciclagem de nutrientes, em área de Caatinga hipoxerófila em Arcoverde, Pernambuco. 2012. 204 f. Tese (Doutorado em Ciências Florestais) - Universidade Federal Rural de Pernambuco, Recife. 2012.

CALIXTO JÚNIOR, J. T.; DRUMOND, M. A. Estrutura fitossociológica de um fragmento de Caatinga sensu stricto 30 anos após corte raso, Petrolina-PE, Brasil. Revista Caatinga, Mossoró, v. 24, n. 2, p. 67-74, 2011.

COSTA, T. C. C.; OlIVEIRA, M. A. J.; ACCIOLY, L. J. O.; SILVA, F. H. B. B. Análise da degradação da Caatinga no núcleo de desertificação do Seridó (RN/PB). Revista Brasileira de Engenharia Agrícola e Ambiental, Campina Grande, v. 13, p. 961-974, 2009.

EMBRAPA - CENTRO NACIONAL DE PESQUISA DE SOLOS. Sistema brasileiro de classificação de solos. Rio de Janeiro: Embrapa - SPI, 2006. 412 p.

EMPARN. EMPRESA DE PESQUISA AGROPECUÁRIA DO RIO GRANDE DO NORTE. Parnamirim - RN, 2013. Disponível em: <http://www.emparn.rn.gov.br/>.

FABRICANTE, J. R.; ANDRADE, L. A. Análise estrutural de um remanescente de Caatinga no Seridó Paraibano. Oecologia Brasiliensis, Rio de Janeiro, v. 11, n. 3, p. 341-349, 2007.

FABRICANTE, J. R.; ANDRADE, L. A.; DIAS TERCEIRO, R. G. Divergências na composição e na estrutura do componente arbustivo-arbóreo entre duas áreas de Caatinga na região do 
submédio São Francisco (Petroline, PE/Juazeiro, BA). Biotemas, Florianópolis, v. 25 n. 3, p. 97-109, 2012.

FREITAS, R. A. C.; SIZENANDO FILHO, F. A.; MARACAJÁ, P. B.; DINIZ FILHO, E. T.; LIRA, J. F. B. Estudo florístico e fitossociológico do estrato arbustivo-arbóreo de dois ambientes em Messias Targino divisa RN/PB. Revista Verde de Agroecologia e Desenvolvimento Sustentável, Mossoró, v. 2, n. 1, p. 135-147, 2007.

KARIN, G.; HAKAN, H. Natural dynamics and regeneration methods in tropical dry forests - An introduction. Journal of Vegetation Science, Xalapa, v. 3, n. 3, p. 361-364, 1992.

KENNARD, D. K.; GOULD, K.; PUTZ, F. E.; FREDERICKSEN, T. S.; MORALES, F. Effect of disturbance intensity on regeneration mechanisms in a tropical dry forest. Forest. Forest Ecology and Management, Amsterdam, v. 162, p. 197-208, 2002.

KÖEPPEN, W. Sistema geográfico dos climas. Notas e comunicado de Geografia - Série B: Textos Didáticos no 13. Recife: Editora Universitária, Departamento de Ciências Geográficas, UFPE, 1996. $31 \mathrm{p}$.

LOPES, C. G. R. Regeneração natural em uma área de agricultura abandonada em ambiente semiárido. 2011. $143 \mathrm{f}$. Tese (Doutorado em Botânica) - Universidade Federal Rural de Pernambuco, Recife. 2011.

MARACAJÁ, P. B.; BATISTA, C. H. F.; SOUSA, A. H.; VASCONCELOS, W. E. Levantamento florístico e fitossociológico do estrato arbustivo-arbóreo de dois ambientes na Vila Santa Catarina, Serra do Mel, RN. Revista de Biologia e Ciências da Terra, Campina Grande, v. 3, n. 2, p. 25-32, 2003.

MATA NATIVA 3. Sistema para análise fitossociológica e elaboração de inventários e planos de manejo de florestas nativas. (Manual do Usuário). Viçosa: Cientec, 2011. 295 p.

MEUNIER, I. M. J.; CARVALHO, J. E. Crescimento da caatinga submetida a diferentes tipos de corte, na Região do Seridó do Rio Grande do Norte. Natal: Projeto MMA/FAO/UTF/BRA/047, 2000. 28 p. (Boletim Técnico n. 4).

MIRANDA, J. D.; PADILLA, F. M.; PUGNAIRE, F. I. Sucesión y restauración en ambientes semiáridos. Ecosistemas, Almería, v. 13, n. 1, p. 55-58, 2004.

PAREYN, F. G. C.; LIMA, K. C.; MARQUES, M. W. C. F.; RIEGELHAUPT, E. M; BACALINI, P. Os recursos florestais nativos e a sua gestão no estado de Pernambuco - o papel do manejo florestal sustentável. In: GARIGLIO, M. A.; SAMPAIO, E. V. S. B.; CESTARO, L. A; KAGEYAMA, P. Y. (Org.). Uso sustentável e conservação dos recursos florestais da Caatinga. Brasília: Serviço Florestal Brasileiro, 2010. p. 229-244.
PASSOS, C. A. M.; BRAZ, E. M. Sistemas silviculturais e agroflorestais na fronteira agrícola da Amazônia. Agrossilvicultura, Viçosa, v. 1, n. 1, p. 91-98, 2004.

PEREIRA, I. M.; ANDRADE, L. A.; COSTA, J. R. M.; DIAS, J. M. Regeneração Natural em um remanescente de Caatinga sob diferentes níveis de perturbação, no Agreste Paraibano. Acta Botanica Brasilica, Feira de Santana, v. 15, n. 3, p. 413-426, 2001. PEREIRA, I. M.; ANDRADE, L. A.; SAMPAIO, E. V. S. B.; BARBOSA, M. R. V. Use-history effects on structure and flora of caatinga. Biotropica, Malden, v. 35, p. 154-165, 2003.

RMFC - REDE DE MANEJO FLORESTAL DA CAATINGA. Protocolo de medições de parcelas permanentes. Recife: Associação de Plantas do Nordeste; Brasília: MMA, PNF, PNE, 2005. 30 p.

RODAL, M. J. N.; SAMPAIO, E. V. S. B.; FIGUEIREDO, M. A. Manual sobre métodos de estudo florístico e fitossociológico ecossistema caatinga. Brasília: Sociedade Botânica do Brasil/Seção Regional de Pernambuco. 1992. 24 p.

SAMPAIO, E. V. S. B.; ARAÚJO, E. A.; SALCEDO, I. H.; TIESSEN, H. Regeneração da vegetação de caatinga após corte e queima, em Serra Talhada, PE. Pesquisa Agropecuária Brasileira, Brasília, v. 33, n. 5, p. 621-632, 1998.

SANTANA, J. A. S.; SOUTO, J. S. Diversidade e estrutura fitossociológica da Caatinga na Estação Ecológica do Seridó - RN. Biologia e Ciências da Terra, João Pessoa, v. 6, n. 2, p. 232-242, 2006.

SANTOS, M. F. A. V.; GUERRA, T. N. F.; SOTERO, M. C.; SANTOS, J. I. N. Diversidade e densidade de espécies vegetais da Caatinga com diferentes graus de degradação no município de Floresta, Pernambuco, Brasil. Rodriguésia, Rio de Janeiro, v. 60, n. 2, p. 389-402, 2009.

SIMON, M. F. Avaliação ecológica rápida para o plano de manejo da Estação Ecológica do Seridó, RN. Brasília: MMA, 2004. s/paginação.

SOUZA, A. L.; SOARES, C. P. B. Florestas nativas: estrutura, dinâmica e manejo. Viçosa: Ed. UFV, 2013. 322 p.

STATISTICA 10. Statistica (Data Analysis Software System), version 10. Tulsa: StatSoft, Inc. 2011.

VIEIRA, D. L. M.; SCARIOT, A. Principles of natural regeneration of tropical dry forests for restoration. Restoration Ecology, Crawley, v. 14, n. 1, p. 11-20, 2006. 